\title{
BMJ Open Primary healthcare usage and use of medications among immigrant children according to age of arrival to Norway: a population-based study
}

\author{
Lars T Fadnes, ${ }^{1,2}$ Esperanza Diaz ${ }^{2,3}$
}

To cite: Fadnes LT, Diaz E. Primary healthcare usage and use of medications among immigrant children according to age of arrival to Norway: a population-based study. BMJ Open 2017;7:e014641. doi:10.1136/bmjopen-2016014641

- Prepublication history and additional material is available. To view please visit the journal (http://dx.doi.org/ 10.1136/bmjopen-2016014641).

Received 12 October 2016 Revised 30 December 2016 Accepted 10 January 2017

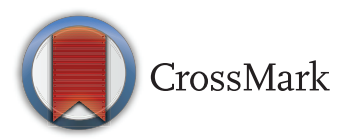

\footnotetext{
${ }^{1}$ Department of Clinical Dentistry, University of Bergen, Bergen, Norway ${ }^{2}$ Department of Global Public Health and Primary Care, University of Bergen, Bergen, Norway

${ }^{3}$ Norwegian Centre for Minority Health Research, Norway
}

Correspondence to Dr Lars T Fadnes; lars.fadnes@uib.no

\section{ABSTRACT}

Background: Morbidity, use of healthcare and medication use have been reported to vary across groups of migrants and according to the different phases of migration, but little is known about children with immigrant background. In this study, we investigate whether the immigrant children's age of arrival predicts differences in usage of primary healthcare (PHC) and in use of prescribed medication.

Methods: This nationwide, population-based study used information for children under 18 years of age in 2008 from three linked registers in Norway. Use of medication was assessed with logistic regression analyses presented with ORs with $95 \% \mathrm{Cls}$.

Results: Of 1168365 children, 119251 had immigrant background. The mean number of PHC visits among children aged 10-18 years, was 1.19 for non-immigrants, 1.17 among second generation immigrants, 1.12, 1.05 and 0.83 among first immigrant children who were $<5,5-9$ and $\geq 10$ years at arrival in Norway, respectively. Patterns were similar for younger immigrants, and were confirmed with regression models adjusting for age and sex. First generation immigrant children used less of nearly all groups of prescribed medication compared to nonimmigrants when adjusting for age and sex (overall $\mathrm{OR}$ $0.48(0.47$ to 0.49$)$ ), and medication was also generally less used among second generation immigrant children (overall OR 0.92 (0.91 to 0.94)).

Conclusions: Age of arrival predicted PHC usage among children among first-generation children. Firstgeneration immigrant children, particularly those arriving later in adolescence, used PHC less than age corresponding non-immigrant children. Immigrant children used less prescribed medication compared to non-immigrants after adjustment for age and sex.

\section{INTRODUCTION}

Increasing mobility has led to 214 million migrants living outside their home countries. ${ }^{1}$ The United Nations declaration of human rights states that all have the right to adequate medical care, independent of

\section{Strengths and limitations of this study}

- Healthcare data were collected with quality control measures in a setting with confidentiality also minimises recall biases and social desirability.

- The study had a national coverage which avoids selection biases, and gives numbers that allow us to classify immigrants in more homogeneous groups.

- Data on unregistered immigrants were not available.

- The study does not include privately provided healthcare, but this type of healthcare is used to limited degree in Norway.

- It was difficult to assess to which degree the health needs of immigrants were met.

national origin. ${ }^{2}$ However, several studies have shown that healthcare access, usage of healthcare services and morbidity varies between non-immigrants and different groups of immigrants, and changes through the different phases of migration. ${ }^{3-5}$ Several studies show that health-seeking behaviour is lower among recently arrived adult immigrants, but increases some years after immigration. $^{6-8}$ One hypothesis is that 'the healthy immigrant effect', which has been reported mostly among adults, ${ }^{9}{ }^{10}$ diminishes with increasing length of stay parallelly with a transition in culture and behavioural patterns $^{11}$ Although the decision process for children is more complex as children's access to healthcare is partially decided by their parents, ${ }^{12}$ our hypothesis was that the healthy migrant effect was present also among children and even more pronounced among the recently arrived first generation children.

Language differences and differences in expressing health problems, as well as insufficient knowledge of organisation and structure of the local health systems, ${ }^{13}$ can also 
constitute barriers hampering the delivery of health services for migrants, especially at arrival. However, this can be counteracted by the use of qualified interpreters making the services more accessible and useful for immigrants, and preventing medical errors. ${ }^{14-17}$ In contrast, some studies point to more blood tests being conducted when there is a lack of immigrant background concordance between the health professional and the patients. ${ }^{7}$ Thus, our hypothesis was that blood tests were used more frequently in assessment of immigrants due to potential communication barriers leading to uncertainty among clinicians.

Although several studies have assessed how different groups of immigrants use primary health services, ${ }^{18}$ fewer have reported on this for children. ${ }^{19} \mathrm{~A}$ study from Norway showed that first generation immigrant children used primary healthcare (PHC) significantly less than non-immigrants when adjusting for age and sex, while second generation immigrant children generally used PHC more. ${ }^{20}$

By comparing non-immigrant children to first and second generation immigrant children living in Norway, this nationwide, population-based study assesses the hypothesis on age of arrival and length of stay as predictors of usage of PHC, use of any blood tests and/or use of interpreter during medical consultations. Further, we compared differences in purchased medication among the same groups.

\section{METHODS}

This study used register data from the National Population Register in Norway (NPR), the Norwegian Health Economics Administration Database (HELFO) and Anatomical Therapeutic Chemical (ATC) codes from the Norwegian Prescription Database (NorPD) for the year $2008 .^{21}{ }^{22}$ These registers were linked using personal identification numbers assigned to all non-immigrants and registered immigrants staying in Norway for at least 6 months. At the time of the study, Norway had a registered population of 4737200 of which 1168000 were children aged 18 years or less. ${ }^{23}$ Immigrants were defined as children with both parents born abroad, and were further classified into first (born abroad) and second generation (born in Norway, but both parents being immigrants) and according to their parents' country of origin information regarding sex, age, country of origin for the child and parents, and age at arrival in Norway was obtained from NPR. We opted not to include children with mixed background with one of the parents from Norway or adopted children with two parents from Norway assuming that these share many similarities with those categorised as non-immigrants as at least one of the parents is familiar with Norwegian culture, traditions and national system structures including the Norwegian healthcare system and to larger extent speak Norwegian at home.

The HELFO database contains administrative claims for PHC for all patient contacts including both contacts with GPs and emergency room (ER). Also from the HELFO database we obtained information regarding use of interpreter and use of any laboratory analyses performed on blood samples. Both the use of interpreter or of any blood tests during consultations in a PHC in the year 2008 were dichotomised (into used vs not used) and assessed only among those who had used a PHC in 2008.

Medication use among children was assessed according to the ATC coding system for antimicrobial medications (J01A-X, J02, J05), hormonal contraceptives (G03A), psychoanaleptics (N06A-B), antiepileptics (N03), non-steroidal anti-inflammatory drugs (NSAIDS, M01A), corticosteroids for dermatological (D07) and nasal use (R01AD), antihistamins (R06), drugs for obstructive airways (R03A, R03BA), immunosuppressants (L04A), insulin (A10A) and thyroid hormones (H03AA). For each ATC group a dichotomised variable indicating if a given ATC group was used in 2008 was created. The Norwegian Prescription Database includes all prescriptions dispensed in Norwegians pharmacies.

In Norway, the health system is structured around GPs providing PHC for a defined group of patients during standard working time while also staffing ER health services for an extended area out-of-hours. GPs are responsible for initial assessments including investigation and treatment of patients of all ages, and refer to secondary care when needed. Children in Norway under the age of 16 years are provided with free healthcare, while those above 16 years of age cover some limited costs.

\section{Analysis}

Descriptive statistics including percentages and means are presented. As the age-of-arrival variable was linked with age, most analyses were conducted in age-restricted groups including only children aged $10-18$ years or with age adjustments, in addition to parallel analyses without restriction made available in online supplementary tables. Relative use of different types of PHC services measured by count variables was analysed with negative binomial regression including unadjusted models and models adjusted by age and sex. Incidence risk ratios (IRR) were calculated with $95 \%$ CIs. Similarly, to compare the use of interpreter and the use of blood tests between first and second generation immigrants and non-immigrants, negative binomial regression models adjusted by age and sex were conducted including only the children who used PCH services in 2008 using a count variable of the outcome. The use of medication was measured as dichotomised variables for each of the ATC groups studied and analysed by logistic regression models adjusted by age and sex to calculate ORs with 95\% CIs. These data are presented in forest plots. Stata SE11 and SPSS V.20.0 were used for statistical analyses.

\section{RESULTS}

Our data comprised 926044 children born in Norway of Norwegian parents and 119251 immigrant children, of 
which 49014 were first generation and 70237 were second generation immigrants (table 1). Among the immigrants, 82006 originated from Asia, Africa and Latin America, 24609 from Eastern Europe, 7012 from Western Europe, 4885 from other Nordic countries and 826 from North America and Oceania. In addition, 123070 children had a mixed background (eg, children with at least one Norwegian parent), and are not presented in the analyses below. First generation children from Asia, Africa and Latin America had moved to Norway at a slightly higher age compared to the other immigrants. The sex distribution was balanced and similar for immigrants and non-immigrants. The mean age was 11.1 years among first generation immigrant children, 7.1 years among second generation immigrant children and 9.3 years among non-immigrants. The correlation coefficient between age at arrival and length of stay without restricting age was -0.36 . In the age restricted groups with children between 10 and 18 years of age, the correlation coefficient was -0.83 .

\section{Use of health services}

The mean number of visits per year to PHC services including GPs, and ER services for children stratified by age at the time of the study (2008) is presented in table 2 and online supplementary table S1. For children 10 years or above in 2008 , the mean number of visits in the same year ranged from 0.83 for those who were 10 years or older at arrival in Norway, 1.17 for second generation immigrants, to 1.19 for non-immigrants. For this group, regression models assessing relative use of PHC indicated slightly less PHC usage among second generation immigrants compared to non-immigrants, and lower usage among first generation immigrants and particularly those arriving as adolescents (table 3). Results including all children are presented in online supplementary table S2, showing higher usage for second-generation immigrants and lower usage for first generation immigrants. In all models, for firstgeneration immigrants there was lower rate of use of PHC as the age of arrival to Norway increased. Immigrants from all regions used PHC less than nonimmigrants, with the largest differences seen among immigrants from North America and Oceania, IRR 0.60 (0.54 to 0.67$)$.

\section{Use of interpreter}

Among children who had attended PHC in 2008, an interpreter was registered for $12.9 \%$ of first generation immigrants and $8.3 \%$ of the second generation immigrants (and among $0.07 \%$ of non-immigrants). An interpreter was more often used among immigrants from Asia, Africa, and Latin America compared to immigrants from Nordic countries (IRR 6.0 (4.6 to 7.8)), and more often among immigrants arriving after 10 years of age compared to second generation immigrants born in Norway (IRR 7.8 (6.9 to 8.8), see online supplementary table S3).

Table 1 Background characteristics of the population included.

\begin{tabular}{|c|c|c|c|c|c|c|c|c|c|c|}
\hline & \multicolumn{2}{|c|}{ Non-immigrants } & \multicolumn{2}{|c|}{$\begin{array}{l}\text { Second } \\
\text { generation }\end{array}$} & \multicolumn{2}{|c|}{ Arrival $<5$ years } & \multicolumn{2}{|c|}{ Arrival 5-9 years } & \multicolumn{2}{|c|}{ Arrival $\geq 10$ years } \\
\hline & $\mathrm{n}$ & Per cent & $\mathrm{n}$ & Per cent & $n$ & Per cent & $\mathrm{n}$ & Per cent & $\mathrm{n}$ & Per cent \\
\hline \multicolumn{11}{|l|}{ Sex of child } \\
\hline Boys & 475250 & 51 & 35975 & 51 & 9099 & 50 & 8629 & 51 & 7343 & 52 \\
\hline Girls & 450794 & 49 & 34309 & 49 & 8975 & 50 & 8217 & 49 & 6791 & 48 \\
\hline \multicolumn{11}{|l|}{ Age in years } \\
\hline $0-1$ & 91127 & 10 & 12657 & 18 & 1202 & 7 & 0 & 0 & 0 & 0 \\
\hline $2-4$ & 135071 & 15 & 15201 & 22 & 5102 & 28 & 0 & 0 & 0 & 0 \\
\hline $5-9$ & 233934 & 25 & 19678 & 28 & 5579 & 31 & 6027 & 36 & 0 & 0 \\
\hline $10-18$ & 465912 & 50 & 22748 & 32 & 6191 & 34 & 10819 & 64 & 14134 & 100 \\
\hline \multicolumn{11}{|l|}{ Area of origin } \\
\hline $\begin{array}{l}\text { Asia, Africa and } \\
\text { Latin America }\end{array}$ & & & 54519 & 78 & 9041 & 50 & 9913 & 59 & 8533 & 60 \\
\hline $\begin{array}{l}\text { North America and } \\
\text { Oceania }\end{array}$ & & & 179 & 0 & 261 & 1 & 206 & 1 & 180 & 1 \\
\hline Nordic countries & & & 2123 & 3 & 1399 & 8 & 877 & 5 & 486 & 3 \\
\hline Norway & 926044 & 100 & & & & & & & & \\
\hline Western Europe & & & 2232 & 3 & 1961 & 11 & 1529 & 9 & 1290 & 9 \\
\hline Eastern Europe & & & 11231 & 16 & 5412 & 30 & 4321 & 26 & 3645 & 26 \\
\hline \multicolumn{11}{|c|}{ World bank income category } \\
\hline Norway-HIC & 926044 & 100 & & & & & & & & \\
\hline $\mathrm{HIC}$ & & & 9805 & 14 & 6945 & 38 & 5861 & 35 & 5073 & 36 \\
\hline MIC & & & 49375 & 70 & 7737 & 43 & 6908 & 41 & 5313 & 38 \\
\hline LIC & & & 11057 & 16 & 3377 & 19 & 4065 & 24 & 3735 & 26 \\
\hline
\end{tabular}

Categories of immigration are grouped depending on age of arrival.

HIC, higher-income country; LIC, lower-income country; MIC, middle-income country. 
Table 2 Number of visits to different primary healthcare services including GP, ER and combined primary healthcare including GP and ER for immigrant children grouped depending on age of arrival in Norway (presented with different age stratifications)

\begin{tabular}{|c|c|c|c|}
\hline & $\begin{array}{l}\text { Use of GP } \\
\text { Mean }\end{array}$ & $\begin{array}{l}\text { Use of ER } \\
\text { Mean }\end{array}$ & $\begin{array}{l}\text { Primary care use } \\
\text { Mean }\end{array}$ \\
\hline \multicolumn{4}{|l|}{ Age stratified 10 years or above } \\
\hline Non-immigrants & 1.06 & 0.13 & 1.19 \\
\hline Second-generation immigrants & 1.05 & 0.12 & 1.17 \\
\hline First generation: $<5$ years at arrival & 1.01 & 0.11 & 1.12 \\
\hline First generation: $5-9$ years at arrival & 0.95 & 0.10 & 1.05 \\
\hline First generation: $\geq 10$ years at arrival & 0.75 & 0.08 & 0.83 \\
\hline \multicolumn{4}{|l|}{ Age stratified $<5$ years } \\
\hline Non-immigrants & 1.76 & 0.30 & 2.06 \\
\hline Second-generation immigrants & 2.16 & 0.45 & 2.60 \\
\hline First generation: $<5$ years at arrival & 1.35 & 0.24 & 1.59 \\
\hline \multicolumn{4}{|l|}{ Age stratified $5-10$ years } \\
\hline Non-immigrants & 1.03 & 0.15 & 1.19 \\
\hline Second-generation immigrants & 1.51 & 0.26 & 1.77 \\
\hline First generation: $<5$ years at arrival & 1.32 & 0.16 & 1.49 \\
\hline First generation: $5-9$ years at arrival & 0.75 & 0.09 & 0.84 \\
\hline \multicolumn{4}{|l|}{ Unstratified } \\
\hline Non-immigrants & 1.23 & 0.18 & 1.40 \\
\hline Second-generation immigrants & 1.62 & 0.29 & 1.91 \\
\hline First generation: $<5$ years at arrival & 1.23 & 0.17 & 1.40 \\
\hline First generation: $5-9$ years at arrival & 0.88 & 0.09 & 0.98 \\
\hline First generation: $\geq 10$ years at arrival & 0.75 & 0.08 & 0.83 \\
\hline
\end{tabular}

Table 3 Relative use of GP's healthcare, ER healthcare and combined primary healthcare including GP and ER reported as IRR with $95 \%$ Cls assessed with negative binomial regression models among children

\begin{tabular}{|c|c|c|c|}
\hline & $\begin{array}{l}\text { Use of GP } \\
\text { IRR }(95 \% \mathrm{Cl})\end{array}$ & $\begin{array}{l}\text { Use of ER } \\
\text { IRR }(95 \% \mathrm{Cl})\end{array}$ & $\begin{array}{l}\text { Primary care use } \\
\text { IRR }(95 \% \mathrm{Cl})\end{array}$ \\
\hline \multicolumn{4}{|l|}{ Model 1: Adjusted by age and sex } \\
\hline Non-immigrants (reference) & 1 & 1 & 1 \\
\hline Second-generation immigrants & 0.96 (0.94 to 0.98$)$ & 0.87 (0.83 to 0.91$)$ & 0.95 (0.93 to 0.97$)$ \\
\hline$<5$ years at arrival & 0.96 (0.95 to 0.98$)$ & 0.89 (0.85 to 0.93$)$ & $0.96(0.94$ to 0.97$)$ \\
\hline $5-9$ years at arrival & $0.76(0.75$ to 0.78$)$ & 0.61 (0.57 to 0.64$)$ & $0.75(0.73$ to 0.76$)$ \\
\hline 10 years or above at arrival & $0.71(0.70$ to 0.73$)$ & $0.64(0.60$ to 0.69$)$ & 0.71 (0.69 to 0.73$)$ \\
\hline \multicolumn{4}{|l|}{ Model 2: adjusted by age and sex } \\
\hline Non-immigrants (reference) & 1 & 1 & 1 \\
\hline Nordic countries & $0.81(0.77$ to 0.85$)$ & $0.77(0.68$ to 0.86$)$ & $0.80(0.76$ to 0.84$)$ \\
\hline Western Europe & $0.66(0.63$ to 0.68$)$ & $0.45(0.40$ to 0.50$)$ & 0.63 (0.61 to 0.66$)$ \\
\hline Eastern Europe & 0.79 (0.78 to 0.81$)$ & 0.77 (0.73 to 0.81$)$ & $0.79(0.77$ to 0.81$)$ \\
\hline North America and Oceania & $0.62(0.55$ to 0.69$)$ & 0.47 (0.35 to 0.62$)$ & $0.60(0.54$ to 0.67$)$ \\
\hline Asia, Africa and Latin America & 0.93 (0.92 to 0.94$)$ & 0.83 (0.80 to 0.85$)$ & 0.92 (0.91 to 0.93$)$ \\
\hline
\end{tabular}

\section{Use of blood tests}

Among those who had used PHC, blood tests were registered in 2008 for $55 \%$ of non-immigrants, $55 \%$ of first generation immigrants and $63 \%$ of second generation immigrants. More specifically, a test for $\mathrm{C}$ reactive protein was registered for $38 \%$ of non-immigrants, $37 \%$ of first generation immigrants and $51 \%$ of second generation immigrants. Blood testing was slightly more often used in consultations with immigrants from Eastern Europe (IRR $1.13 \quad(1.10$ to 1.15$)$, see online supplementary table S4) and Asia, Africa and Latin America (IRR 1.17 (1.16 to 1.19)) compared to nonimmigrants, but less often among immigrants from North America and Oceania (IRR 0.75 (0.64 to 0.87)) and Western Europe (IRR 0.82 (0.78 to 0.86)). Blood testing was also more often used among second 
generation immigrants compared to non-immigrants (IRR 1.24 (1.22 to 1.25), but slightly less used among generation immigrants (IRR 0.95 (0.93 to 0.96 ).

\section{Use of medications}

When studying children 10 years or older in 2008 , first generation immigrants used less of nearly all assessed groups of prescribed medications compared to nonimmigrants when adjusting for age and sex, with an overall OR of 0.48 (0.47 to 0.49 ) (figure 1$)$. The overall pattern among second generation immigrant children aged 10 years or above was less use of medications compared to non-immigrants (OR 0.92 (0.91 to 0.94), figure 2). Similar patterns, but with higher use of antimicrobials in second generation children, were observed when including all ages in the analyses (see online supplementary figure S1 and S2). In the adjusted analysis of each of the ATC groups separately, first generation children used less off all assessed medications than non-immigrants, while second generation immigrant children used more dermatological and nasal corticosteroids when including only those 10 years and older and also slightly more antimicrobial medications and antihistamins when including all children. In all age groups, second generation children used less antiepileptics, psychoanaleptics, hormonal contraceptives, insulin and NSAIDS compared to non-immigrants (see online supplementary tables S5 and S6).

\section{DISCUSSION}

Immigrant children in this study used PHC and medication significantly less than non-immigrants when adjusting for age and sex. The lowest use was registered for first generation immigrants and especially children arriving later in childhood. All immigrants groups used PHC less often than non-immigrants with the largest difference between immigrants from North America and Oceania and non-immigrants. Among those attending to PHC, an interpreter was used significantly more often among first generation immigrants from Asia, Africa and Latin America and blood tests were used slightly more often for second generation immigrants compared to non-immigrants, with no differences between first generation immigrants compared to non-immigrants.

The observed differences in PHC and medication usage could have various causes. On the one hand, our results fit with our hypothesis that 'the healthy immigrant effect' reported among adults ${ }^{9}{ }^{10}$ is more important for immigrant children who arrive in Norway at an older age correlating. However, it should be noted that age of arrival for first generation immigrant children will correlate with length of stay in these data-particularly for analyses using narrow age strata. In these data we cannot fully distinguish between effects related to age of arrival and length of stay effects. Length of stay has been found to be strongly associated with healthcare use in other settings. ${ }^{8}$ According to the healthy migrant

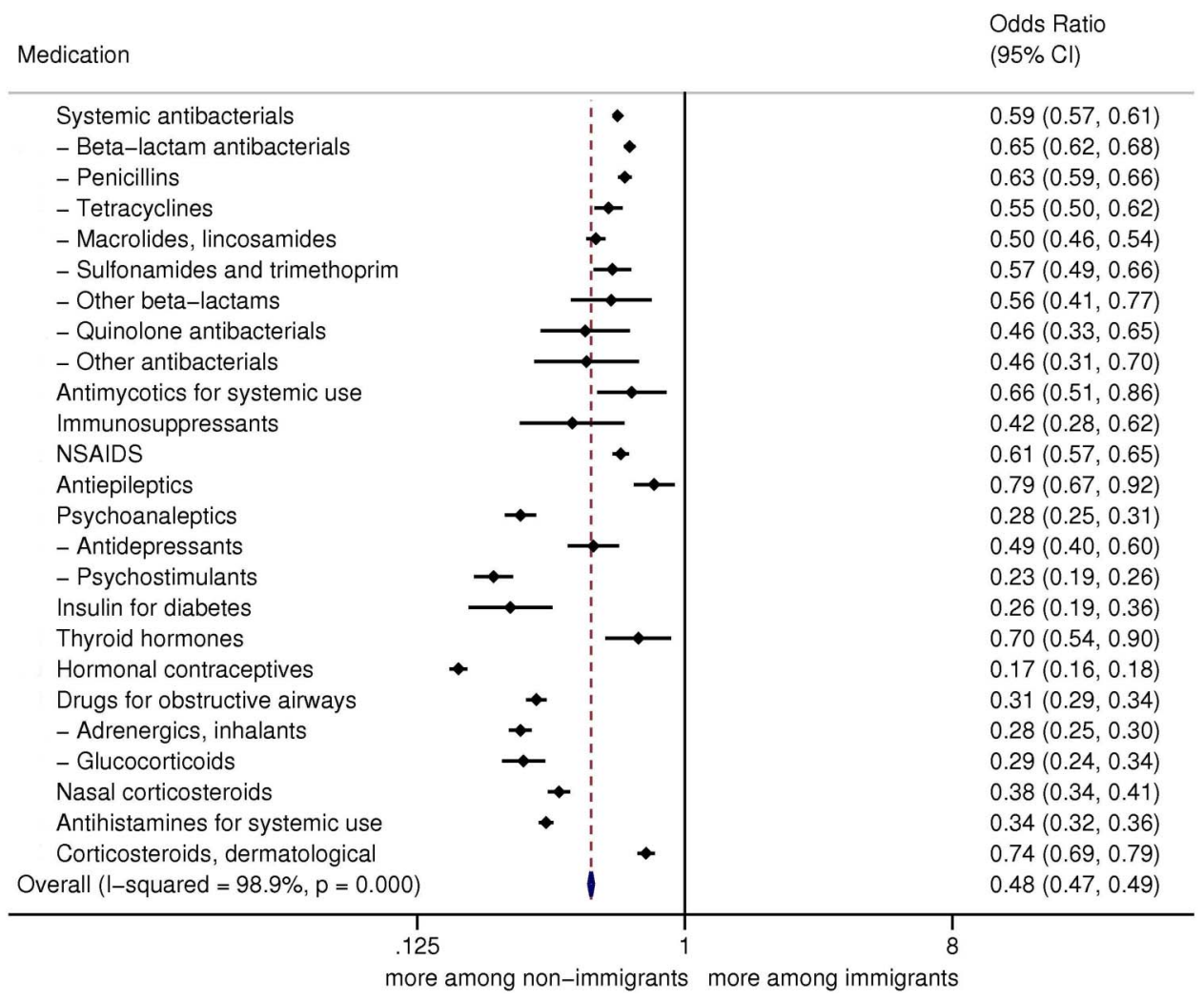

Figure 1 Forest plot presenting differences in use of several groups of medications adjusted for age and sex reported as ORs with $95 \% \mathrm{Cls}$ assessed with logistic regression models. Comparisons are done between non-immigrants and first-generation immigrants (restricted to current age of 10 years or above). NSAIDs, non-steroidal anti-inflammatory drugs. 


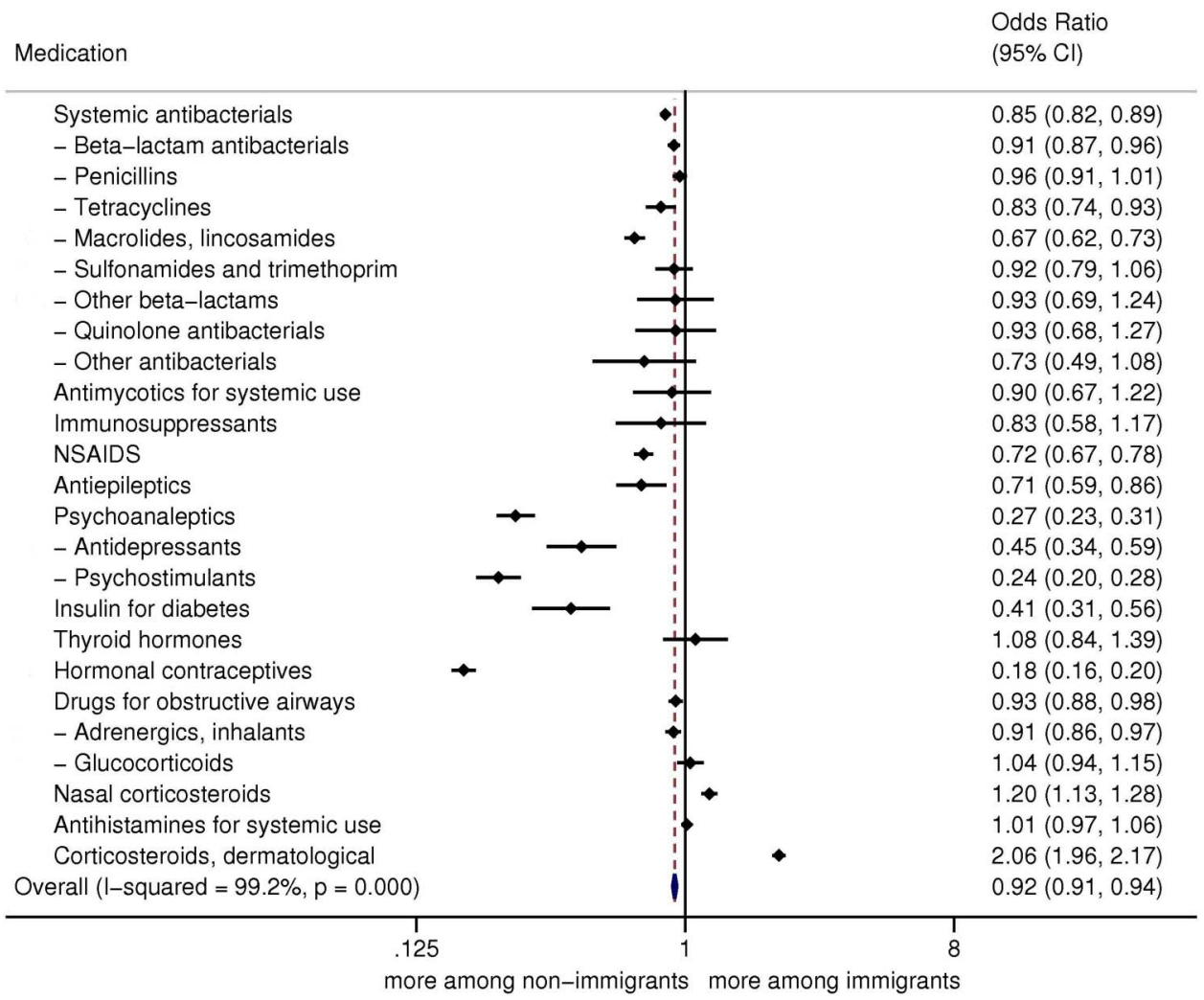

Figure 2 Forest plot presenting differences in use of different group of medications adjusted for age and sex reported as ORs with $95 \% \mathrm{Cls}$ assessed with logistic regression models. Comparisons are done between non-immigrants and second-generation immigrants (restricted to current age of 10 years or above). NSAIDs, non-steroidal anti-inflammatory drugs.

theory there might be a degree of selection among immigrants in morbidity. Regarding first generation immigrant children, it is not unlikely that the sickest children, especially the youngest ones, do not start or complete their journeys, while among second generation children, who are born in Norway, this selection effect, if at all present, would only apply through the previous selection of their parents. Furthermore, statistics from Norway indicate that immigrant infants born in Norway with mothers from low-income countries have higher mortality than children with non-immigrants background, ${ }^{24}$ which would accord to our results of second generation children using the system more when including also the youngest children in the analyses. Another possible explanation for our findings could be that the stress and strain associated with the immigration process itself have more severe health consequences for small children than for teen-age children causing more health-seeking behaviour in this group. In favour of this hypothesis, a review summarising trauma among refugees indicated slightly higher burden among refugees arriving during adolescence than as adults. ${ }^{25}$ On the other hand, acculturation is generally quicker in younger age contributing to reducing the stress. ${ }^{26}$

However, differences in morbidity among the children might not be the only explaining factor. As parents often have a strong degree of influence on when children should seek healthcare, ${ }^{12}$ parallel patterns between children and adults in PHC usage would not be surprising. Studies have shown that adults increase their use of PHC with increasing length of stay in the country, ${ }^{27}$ and this could also affect second generation children, whose parents have lived longer in Norway. Also, a Danish study showing differences in vaccination between different immigrant groups indicated that perceptions and knowledge contribute to differences in use of health services. ${ }^{28}$

The variations in use of medication might also be due to differences in the parents' perceptions or knowledge on use of medications, or to financial barriers to access medicines. As adjusting for number of health visits gave similar results (results not shown), it is unlikely that variation in health-seeking behaviour alone explains the differences in medication use. It is possible that immigrants to a stronger degree buy medications abroad. However, the difference in medication use between first generation immigrant children and non-immigrants was more pronounced for drugs for chronic disease such as obstructive airways and psychoanaleptics, which to larger degree are covered by public funding in Norway and less for systemic antibacterial medications, which could indicate that financial barriers are less important in explaining the differences in prescribed medications. Other reasons to explain less use of medication could be that the first generation immigrant children lived with higher degree of morbidity without seeking help, or less response to 
medications due to genetic differences between groups from various ethnicities, such as generally less effect of commonly used medications for asthma among those of African ancestry. ${ }^{29}$ Our results are in accordance with studies among children in Sweden, the Netherlands and Spain that have shown lower usage of prescribed medications among first generation immigrant children compared to non-immigrants. ${ }^{50-34}$

An interpreter had been used for about a tenth of the immigrant children, mostly among immigrants from Asia, Africa and Latin America, who were more likely to have larger differences in language and culture, and also more among those arriving in Norway during adolescence having had fewer years to adjust culturally and linguistically compared with those arriving earlier. This corresponds well with the findings from Canada indicating that those with language proficiency and who had stayed in Canada for 10 years or more used healthcare more than those who had not. ${ }^{8} 17$ Even though interpreters were commonly used among children with background from low-income countries arriving in adolescence, the language barrier might still have contributed to reduced usage. The more frequent use of blood tests among second generation immigrants and mainly from Asia, Africa and Latin America could fit with the hypothesis of a larger language and cultural barrier leading to a higher degree of clinical uncertainty among healthcare providers. Another possibility could be that the clinicians are less experienced to meet the needs of immigrants, ${ }^{35}$ but could also be linked with differences in expectations among the patients.

It is likely that the health-seeking behaviour and the procedures taking place in the consultations are influenced to different degree by clinicians, the children and their care takers. ${ }^{12}$ Even though the clinicians are the ones making decisions on the use of blood tests and interpreters in the consultations, choices are also influenced by the children and their caretakers. ${ }^{8}$

Similarly, caretakers and their children are usually the main decision makers in health-seeking behaviour, but this is also influenced by both the clinicians and other factors. ${ }^{17}$

Our study have several strengths including its national coverage limiting selection biases, and numbers that allow us to classify immigrants in groups according to age of arrival while ensuring sufficient analytic power even though heterogeneity inside groups still exists. The use of healthcare registered data collected with several quality control measures in a setting with confidentiality also minimises recall biases, social desirabilityand contributes to good data quality for many of the included variables. However, our study also has some limitations. As it is based on national registers, unregistered immigrants are not included, whose healthcare access is likely to be lower. ${ }^{36}$ It is also difficult to assess to which degree the health needs of immigrants are met. Some variables that could have been useful, such as sociodemographic variables of the family, were not possible to link to the children included.
Data on these among adults in Norway show that immigrants particularly from low-income countries more often had a lower income and education than nonimmigrants. ${ }^{37}$ We would expect the same to be true for the parents of the included children. Our study does not include privately provided healthcare, but this type of care is used to limited degree in Norway.

In conclusion, this study supports the hypothesis that age of arrival or length of stay predicts PHC usage for children. Immigrant children used PHC less than age corresponding non-immigrant children, particularly among first generation children arriving later in adolescence. First generation immigrant children used less of nearly all groups of prescribed medications compared to non-immigrants when adjusting for age and sex. The differences in PHC usage between non-immigrants and second generation immigrant children were mostly linked to differences in age, with overall slightly less use of prescribed medications among second generation immigrant children. Regarding the use of any blood tests in PHC, the picture was more mixed with slightly more use among immigrants with larger language differences and less use among other immigrants.

Contributors LTF participated in design and implementation of the study, analysis and interpretation of data and writing of the manuscript. ED took part in design and implementation, analysis, interpretation of data and co-writing of the manuscript.

Funding The authors LTF and ED were employed by the University of Bergen. Competing interests None declared.

Ethics approval This study is part of the project 'Immigrants' health in Norway' Regional Committee for Medical and Health Research Ethics, the Norwegian Data Inspectorate, the Norwegian Labour Welfare Service and the Norwegian Directorate of Health.

Provenance and peer review Not commissioned; externally peer reviewed.

Data sharing statement No additional data are available.

Open Access This is an Open Access article distributed in accordance with the Creative Commons Attribution Non Commercial (CC BY-NC 4.0) license, which permits others to distribute, remix, adapt, build upon this work noncommercially, and license their derivative works on different terms, provided the original work is properly cited and the use is non-commercial. See: http:// creativecommons.org/licenses/by-nc/4.0/

\section{REFERENCES}

1. Oberoi $\mathrm{P}$, Sotomayor J, Pace $\mathrm{P}$, et al. International Migration, Health and Human Rights. International Organization for Migration (IOM). International Organization for Migration (IOM), World Health Organization, UNOHCHR, 2013.

2. The United Nations. The Universal Declaration of Human Rights. UN General Assembly, Paris, 1948.

3. Rechel B, Mladovsky P, Ingleby D, et al. Migration and health in an increasingly diverse Europe. Lancet 2013;381:1235-45.

4. Wolfe I, Thompson M, Gill P, et al. Health services for children in Western Europe. Lancet 2013;381:1224-34.

5. Gimeno-Feliu LA, Armesto-Gomez J, Macipe-Costa R, et al. Comparative study of paediatric prescription drug utilization between the Spanish and immigrant population. BMC Health Serv Res 2009;9:225

6. Diaz E, Kumar BN, Gimeno-Feliu LA, et al. Multimorbidity among registered immigrants in Norway: the role of reason for migration and length of stay. Trop Med Int Health 2015;20:1805-14.

7. Sandvik H, Hunskaar S, Diaz E. Immigrants' use of emergency primary health care in Norway: a registry-based observational study. BMC Health Serv Res 2012;12:308. 
8. Lebrun LA. Effects of length of stay and language proficiency on health care experiences among immigrants in Canada and the United States. Soc Sci Med 2012;74:1062-72.

9. Linton JM, Choi R, Mendoza F. Caring for children in immigrant families: vulnerabilities, resilience, and opportunities. Pediatr Clin North Am 2016;63:115-30

10. Gimeno-Feliu LA, Calderon-Larranaga A, Diaz E, et al. The healthy migrant effect in primary care. Gac Sanit 2015;29:15-20.

11. McDonald JT, Kennedy S. Insights into the 'healthy immigrant effect': health status and health service use of immigrants to Canada. Soc Sci Med 2004;59:1613-27.

12. Coyne I. Children's participation in consultations and decision-making at health service level: a review of the literature. Int J Nurs Stud 2008;45:1682-9.

13. Agudelo-Suarez AA, Gil-Gonzalez D, Vives-Cases C, et al. A metasynthesis of qualitative studies regarding opinions and perceptions about barriers and determinants of health services' accessibility in economic migrants. BMC Health Serv Res 2012;12:461.

14. Cohen AL, Rivara F, Marcuse EK, et al. Are language barriers associated with serious medical events in hospitalized pediatric patients? Pediatrics 2005;116:575-9.

15. Flores G, Laws MB, Mayo SJ, et al. Errors in medical interpretation and their potential clinical consequences in pediatric encounters. Pediatrics 2003;111:6-14.

16. Karliner LS, Jacobs EA, Chen AH, et al. Do professional interpreters improve clinical care for patients with limited English proficiency? A systematic review of the literature. Health Serv Res 2007;42:727-54.

17. Leduc N, Proulx M. Patterns of health services utilization by recent immigrants. J Immigr Health 2004;6:15-27.

18. Uiters $\mathrm{E}$, Deville W, Foets $\mathrm{M}$, et al. Differences between immigrant and non-immigrant groups in the use of primary medical care; a systematic review. BMC Health Serv Res 2009;9:76.

19. Ballotari $P$, D'Angelo $S$, Bonvicini $L$, et al. Effects of immigrant status on Emergency Room (ER) utilisation by children under age one: a population-based study in the province of Reggio Emilia (Italy). BMC Health Serv Res 2013;13:458.

20. Fadnes LT, Moen KA, Diaz E. Primary healthcare usage and morbidity among immigrant children compared with non-immigrant children: a population-based study in Norway. BMJ Open 2016;6: e012101.

21. Statistics Norway (Statistisk sentralbyrå). Classification of centrality. 2013. http://www.ssb.no/metadata/conceptvariable/vardok/927/en

22. Furu K. Establishment of the nationwide Norwegian Prescription Database (NorPD) - new opportunities for research in pharmacoepidemiology in Norway. Norw J Epidemiol 2008;18: 129-36.
23. Statistics Norway (Statistisk sentralbyrå). Population, 1 January 2008 http://ssb.no/en/befolkning/statistikker/folkemengde/aar/2008-03-13

24. Kinge JM, Kornstad T. Assimilation effects on infant mortality among immigrants in Norway Statistics Norway, Research Department. Statistics Norway, 2013.

25. Fazel M, Wheeler J, Danesh J. Prevalence of serious mental disorder in 7000 refugees resettled in western countries: a systematic review. Lancet 2005;365:1309-14.

26. American Psychological Association (APA) Presidential Task Force on Immigration. Crossroads: the psychology of immigration in the new century. 2012. http://www.apa.org/topics/immigration/report.aspx

27. Diaz E, Calderón-Larrañaga A, Prado-Torres A, et al. How do immigrants use primary healthcare services? A register-based study in Norway. Eur J Public Health 2015;25:72-8.

28. Moller SP, Hjern A, Andersen AM, et al. Differences in uptake of immunisations and health examinations among refugee children compared to Danish-born children: a cohort study. Eur J Pediatr 2016;175:539-49.

29. Ortega VE, Meyers DA. Pharmacogenetics: implications of race and ethnicity on defining genetic profiles for personalized medicine. J Allergy Clin Immunol 2014;133:16-26.

30. Braback L, Vogt $\mathrm{H}$, Hjern A. Migration and asthma medication in international adoptees and immigrant families in Sweden. Clin Exp Allergy 2011;41:1108-15.

31. Van Leeuwen W, Nilsson S, Merlo J. Mother's country of birth and prescription of psychotropic medication in Swedish adolescents: a life course approach. BMJ Open 2012;2:pii: e001260.

32. de Bot CM, Moed H, Schellevis FG, et al. Allergic rhinitis in children: incidence and treatment in Dutch general practice in 1987 and 2001. Pediatr Allergy Immunol 2009;20:571-7.

33. van Dellen QM, Stronks K, Bindels PJ, et al. Predictors of asthma control in children from different ethnic origins living in Amsterdam. Respir Med 2007;101:779-85.

34. Macipe Costa RM, García-Campayo J, Gimeno-Feliu L, et al. Differences in Methylphenidate Use between Immigrants and Spaniards in the Child Population of Aragon, Spain: a retrospective study. J Child Neurol 2011;26:1265-70.

35. Adams KM, Gardiner LD, Assefi N. Healthcare challenges from the developing world: post-immigration refugee medicine. BMJ 2004;328:1548-52.

36. Karlsen M-A. Precarious inclusion. Irregular migration, practices of care, and state bordering in Norway. University of Bergen, 2015.

37. Diaz E, Gimeno-Feliu LA, Calderon-Larranaga A, et al. Frequent attenders in general practice and immigrant status in Norway: a nationwide cross-sectional study. Scand J Prim Health Care 2014;32:232-40. 